\title{
Efficient and selective hydrolysis of 4-nitrophenyl phosphate by a dinuclear copper(II) complex
}

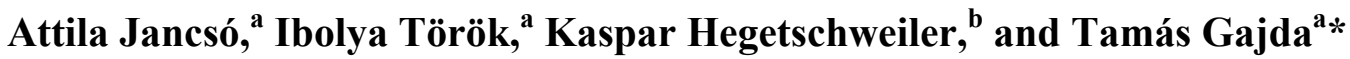 \\ ${ }^{a}$ Department of Inorganic and Analytical Chemistry, University of Szeged, H-6701 Szeged, P.O. \\ Box 440, Hungary \\ ${ }^{b}$ Anorganische Chemie, Universität des Saarlandes, D-66041 Saarbrücken, Postfach 151150, \\ Germany \\ E-mail:gajda@,chem.u-szeged.hu
}

\section{Dedicated to Prof. Harri Lönnberg on his $60^{\text {th }}$ birthday}

\begin{abstract}
The aim of this work was to construct chemical models for selective hydrolysis of phosphate monoesters in order to elucidate the role of metal ions in the hydrolytic mechanisms and to develop artificial enzymes for practical applications. A dinuclear copper(II) complex of a cyclohexane-based polyamino polyalcohol provided a selective and by far the highest rate acceleration among the transition metal complexes containing divalent metal ions for the hydrolysis of a phosphate monoester.
\end{abstract}

Keywords: Selective phosphomonoester hydrolysis, dinuclear copper(II) complexes, kinetic studies, cyclic polyamino polyalcohol

\section{Introduction}

Dinuclear complexes as chemical models of phosphodiesterases have attracted great interest in the last years in order to elucidate the role of metal ions in the hydrolytic mechanisms, ${ }^{1}$ and to develop artificial nucleases, ${ }^{2}$ which may have important applications in biotechnology and chemotherapy. Highly active complexes have been achieved by creating dinuclear centers of iron(III), ${ }^{3}$ cobalt(III), ${ }^{4}$ copper(II) ${ }^{5}$ zinc(II) ${ }^{6}$ and lanthanide(III) ${ }^{7}$ ions. Much less attention has been paid to the selective hydrolysis of phosphate monoesters by metal complexes, although their hydrolysis is of central importance to the biochemistry of living cells. Though some

cobalt(III) $^{4,8}$ or lanthanide(III) ${ }^{7}$ complexes provide important rate acceleration for phosphate monoesters, their action is not selective, since they exert similar effect on the diesters, too. On the other hand, highly active mimics of phosphodiesterases containing divalent transition metal 
ions are either inactive, ${ }^{9}$ or provide considerably reduced rate acceleration for phosphomonoester hydrolysis ${ }^{5 b}$ due to the higher negative charge of the substrates. A notable exception has been reported by Kimura et al. ${ }^{10}$ An alkoxide bridged dizinc(II) complex of an octaazacryptand selectively hydrolyses phosphate monoesters with moderate activity.

Cyclohexane-based polyamino polyalcohols have been shown to possess several unique coordination properties, ${ }^{11}$ providing excellent possibilities for the design of tailored chelating agents which exert influence on the structure, stability, and electronic properties of the metal complexes. We have recently reported, that the dinuclear copper(II) and zinc(II) complexes of 1,3,5-trideoxy-1,3,5-tris(dimethylamino)-cis-inositol (tdci) provide outstanding rate acceleration for the hydrolysis of the activated phosphodiester bis(4-nitrophenyl)-phosphate (BNPP), ${ }^{5 b}$ nucleoside 2',3'-cyclic monophosphates and dinucleoside monophosphates. ${ }^{12}$ The dinuclear copper(II) complex possesses considerably lower efficiency toward the hydrolysis of the phosphate monoester 4-nitrophenyl phosphate (NPP). ${ }^{5 b}$ The related monomethylated ligand 1,3,5-trideoxy-1,3,5-tris(methylamino)-cis-inositol (tmci) is less rigidly preorganized than tdci, due to the decreased intraligand repulsions between the methylamino groups, which may strongly influence the properties of their metal complexes. Indeed, in contrast to tdci, the oligonuclear zinc(II) complexes of tmci do not promote the hydrolysis of dinucleoside monophosphates, but allow selective cleavage of the triphosphate moiety of mRNA 5'-cap units. $^{13}$

Both enzymatic and non-enzymatic hydrolysis of phosphate monoesters proceed via looser transition states compared to diesters. ${ }^{14}$ Monoester hydrolysis could be favored over the diester by its stronger binding interaction to metal ions, and by e.g. subtle differences in the electrostatic properties of the bimetallic core, in the coordinating ligands, or in the metal-metal separation. ${ }^{14}$ Consequently, the substrate selectivity of the highly efficient phosphodiesterase mimic copper(II)-tdci complexes may be fine tuned by changing slightly the ligand properties, e.g. by using a related but somewhat more flexible ligand. Therefore, here we report the hydrolysis of 4nitrophenyl phosphate (NPP) promoted by a dinuclear copper(II) complex of 1,3,5-trideoxy1,3,5-tris(methylamino)-cis-inositol (tmci).

\section{Results and Discussion}

Since the dinuclear $\mathrm{Cu}_{2} \mathrm{H}_{-3}$ tdci complex promoted very efficiently the hydrolysis of the phosphodiester bis(4-nitrophenyl)phosphate (BNPP), ${ }^{5 b}$ first we tested the kinetic activity of the copper(II)-tmci complexes using BNPP as substrate. After a fast, saturation-like increase of the absorbance at $400 \mathrm{~nm}(\Delta A \sim 0.15$ within $2000 \mathrm{~s})$, the formation of 4-nitrophenolate slows down, but shows linear time-dependence. Using the absorbance data detected between 4000 and $6000 \mathrm{~s}$, $k_{\text {obs }}=2.8 \times 10^{-7} \mathrm{~s}^{-1}$ can be calculated $\left(\mathrm{pH}=8.2, c_{\text {tmci }}=0.5 \times c_{\text {CuII }}=1.05 \times 10^{-3} \mathrm{M}, c_{\mathrm{BNPP}}=1.5 \times 10^{-3}\right.$ M). Under similar conditions $k_{\mathrm{obs}}=7.0 \times 10^{-4} \mathrm{~s}^{-1}$ was determined in the copper(II)-tdci system, ${ }^{5 \mathrm{~b}}$ reflecting 2500-fold higher activity of the latter complexes. The initial fast increase of the 
absorbance was attributed to the rapid hydrolysis of NPP present as impurity $(\sim 0.5 \%)$ in BNPP. Therefore detailed kinetic studies have been performed only with the phosphomonoester NPP.

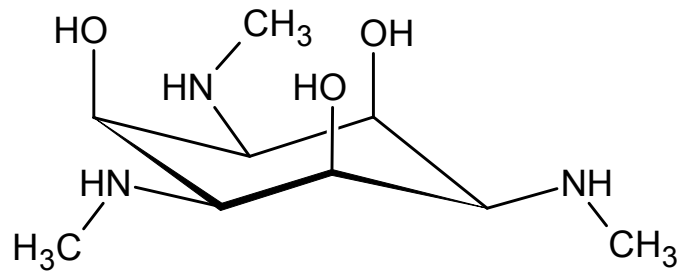

Scheme 1. The structure of tmci.

Results of some preliminary kinetic runs showed that in the presence of tmci and copper(II) the fastest cleavage of NPP occurred around $\mathrm{pH}$ 8. Due to its specific donor group arrangement, tmci has three facial $\{\mathrm{O}, \mathrm{N}, \mathrm{O}\}$ coordination sites (Scheme 1) and is able to bind up to three metal ions, by the formation of alkoxo-bridge between two adjacent metal ions. In order to determine the composition of the hydrolytically active species, we measured the pseudo-first order rate constants of NPP hydrolysis as a function of the copper(II) - ligand ratio at pH 7.8 (Figure 1).

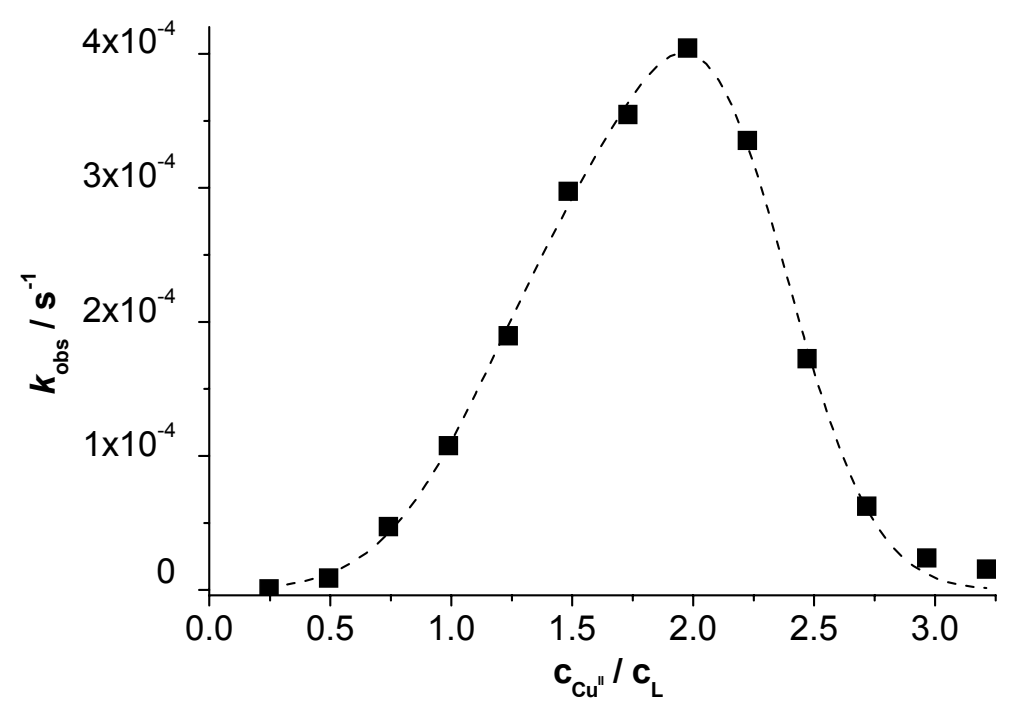

Figure 1. $k_{\mathrm{obs}}$ values for the hydrolysis of NPP as a function of copper(II)-to-tmci ratio ( $\mathrm{pH}=$ $7.8, c_{\mathrm{tmci}}=4.5 \times 10^{-4} \mathrm{M}, c_{\mathrm{NPP}}=1.25 \times 10^{-4} \mathrm{M}, T=298 \mathrm{~K}$, the dashed line simply connects the points to show the tendency).

The profile shows a slightly distorted bell-shape having a maximum at twofold excess of copper(II) over the ligand. Below and above this ratio the rate constants decrease in a monotonic way, nevertheless, there is $\sim 30 \%$ residual activity even at 1:1 ratio of the components. These data suggest that similarly to our previous results with the zinc(II) complexes of tmci ${ }^{13}$ and the 
copper(II) complexes of tdci, ${ }^{5 b}$ dinuclear complex(es) possess(es) the highest kinetic activity. However, in the present case the dinuclear complex(es) selectively hydrolyse(s) the phosphomonoester NPP. Based on solely the kinetic results, the contribution of mononuclear species to the observed kinetic activity at 1:1 metal-to-ligand ratio cannot be ruled out. Trinuclear species seemingly have a minor impact, if any, on the cleavage rate. The autohydrolysis of NPP around $\mathrm{pH} 8$ is very slow ${ }^{15}$ and thus can be neglected compared to the process promoted by the complex(es).

The $\mathrm{pH}$-dependence of the hydrolysis has been screened at the optimal 2:1 copper(II) - tmci ratio (Figure 2). The $\mathrm{pH}$ - rate constant profile is a distorted bell-shaped curve, with an optimum around $\mathrm{pH}$ 7.8. This observation suggests the formation of the reactive species between $\mathrm{pH}$ 6-7.5, then its subsequent transformation into an inactive one.

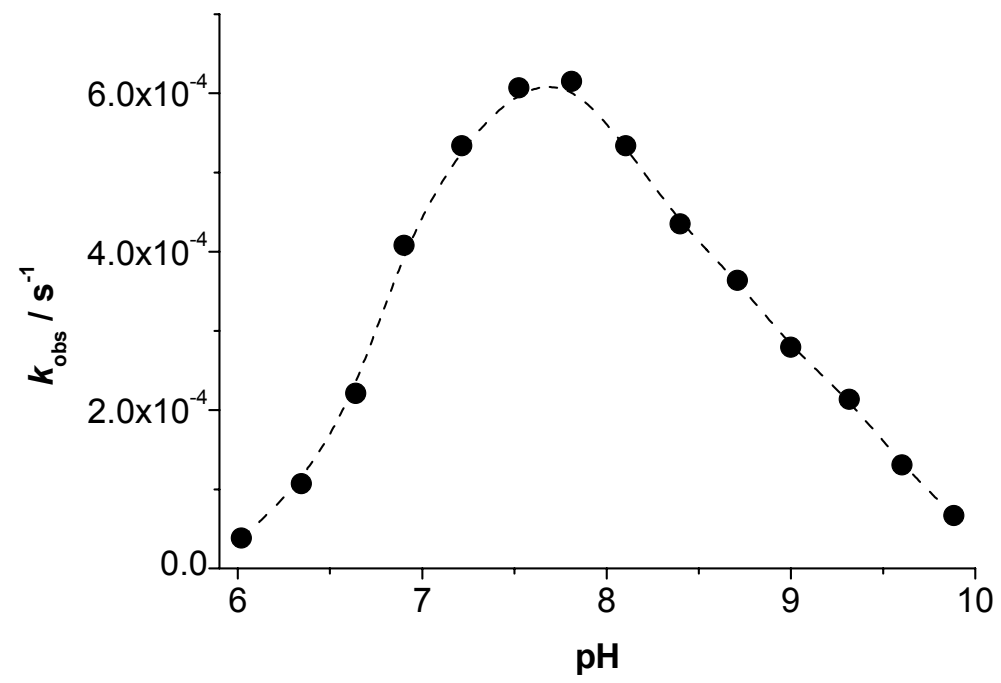

Figure 2. $\mathrm{pH}$-dependence of the $k_{\mathrm{obs}}$ values for the hydrolysis of NPP in the copper(II) - tmci $2: 1$ system $\left(c_{\mathrm{NPP}}=1.25 \times 10^{-4} \mathrm{M}, c_{\mathrm{tmci}}=5.0 \times 10^{-4} \mathrm{M}, T=298 \mathrm{~K}\right.$, the dashed line simply connects the points to show the tendency).

Reversed saturation kinetic experiments by increasing the complex/substrate ratio at a constant substrate concentration and at $\mathrm{pH} 7.8$ have also been performed to better characterize the kinetic behaviour of the copper(II) - tmci system (Figure 3). The ratio of copper(II) and the ligand was kept at a constant 2:1 value, and their total concentration was increased up to 72-fold excess over NPP. Above 30-fold excess of the dinuclear complex(es) over the substrate a clear saturation was observed (Figure 3). This indicates a fast pre-equilibrium related to the formation of an intermediate substrate-complex adduct, followed by the rate determining transformation of the substrate within this complex. The experimental points for the observed initial rates $\left(V_{0}\right)$ were fitted by Equation (1): 


$$
V_{0}=\frac{k_{\mathrm{cat}} \cdot K_{1} \cdot[\mathrm{C}] \cdot[\mathrm{S}]_{0}}{1+K_{1} \cdot[\mathrm{C}]}
$$

where $K_{1}$ is the stability constant of the intermediate substrate-dinuclear complex adduct, $k_{\text {cat }}$ is the first-order rate constant for the hydrolysis of NPP inside this complex (catalytic rate constant), $[\mathrm{C}]$ is the concentration of the kinetically active dinuclear complex and $[\mathrm{S}]_{0}$ stands for the initial concentration of the substrate NPP. At present, the data depicted in Figure 3 can be evaluated only by assuming $[\mathrm{C}]=c_{\mathrm{tmci}}$, i.e. the presence of a single species at $\mathrm{pH}=7.8$. Using this assumption and Equation (1), the experimental data allowed us to calculate the lower limit of both $k_{\text {cat }}\left(=1.45 \times 10^{-3} \mathrm{~s}^{-1}\right)$ and $K_{1}\left(=1000 \mathrm{M}^{-1}\right)$. Considering the rate of autohydrolysis at $\mathrm{pH}$ $7.8\left(k_{\text {auto }}=4.9 \times 10^{-9} \mathrm{~s}^{-1}\right.$, extrapolated to $25{ }^{\circ} \mathrm{C}$ from the data given in Ref. 15$)$, the above $k_{\text {cat }}$ value represents a remarkably efficient, at least $3 \times 10^{5}$-fold rate enhancement induced by the dinuclear complex(es) of tmci.

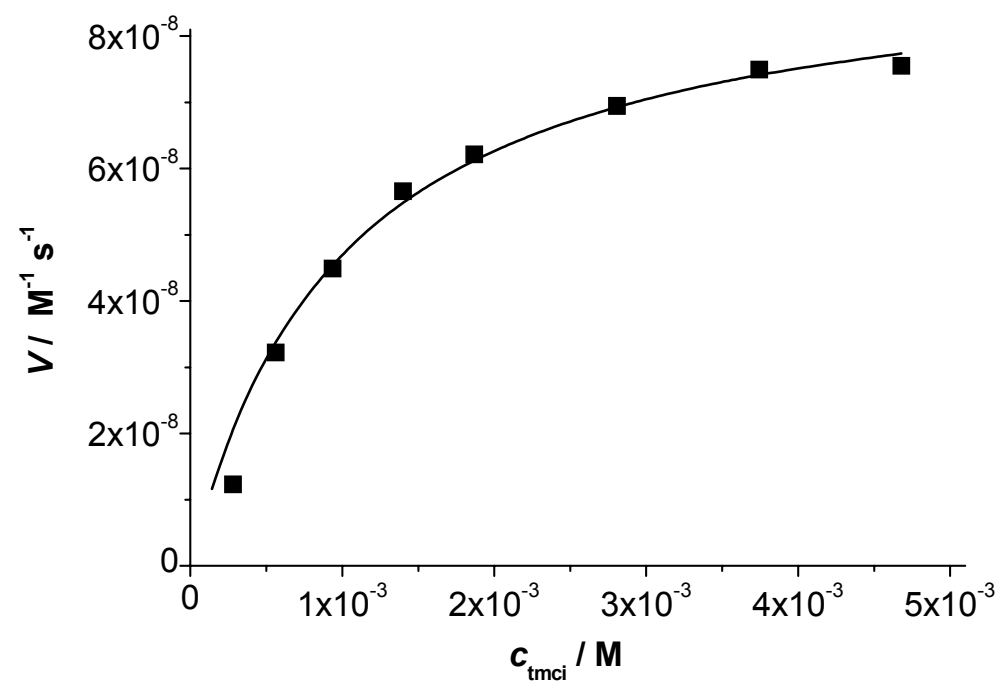

Figure 3. Dependence of the initial rates of NPP hydrolysis on the total concentration of the ligand (and the metal ion) in the copper(II) - tmci $2: 1$ system at $\mathrm{pH}=7.8\left(c_{\mathrm{NPP}}=6.5 \times 10^{-5} \mathrm{M}, T\right.$ $=298 \mathrm{~K}$, the continuous line is a fitted curve to the experimental points).

The above $K_{1}$ value indicates rather strong binding of NPP to the dinuclear copper(II) complex(es). To verify this finding we investigated the electronic spectra of the ternary copper(II) - tmci - phenyl phosphate (PP) system, since PP is a close mimic of NPP but hydrolytically more resistant. The spectra with increasing phenyl-phosphate to dinuclear complex(es) ratios at $\mathrm{pH} 8$ are depicted in Figure 4. 


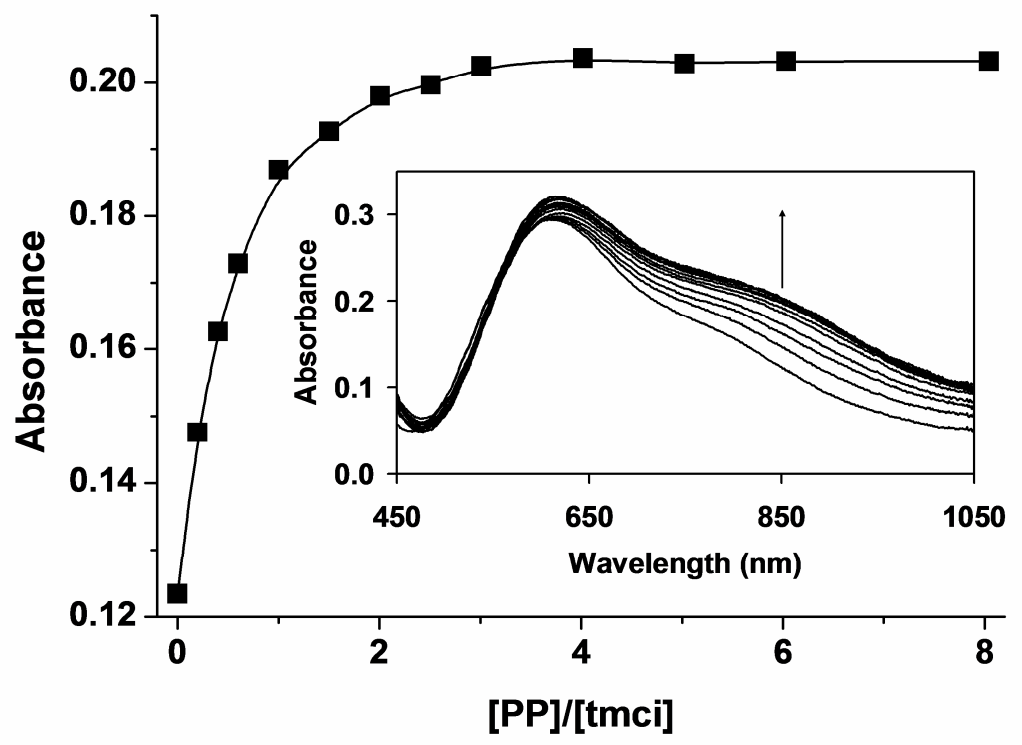

Figure 4. The change of the absorbance at $\lambda=850 \mathrm{~nm}$ as a function of the $\mathrm{PP} /$ tmci ratio $(\mathrm{pH}=$ $\left.8.0, c_{\text {tmci }}=0.5 \times \mathrm{c}_{\text {copper(II) }}=2.82 \times 10^{-3} \mathrm{M}, T=298 \mathrm{~K}\right)$. The insert shows the full spectra of $\mathrm{d}-\mathrm{d}$ bands.

In the absence of PP, the $d-d$ bands have a maximum at $620 \mathrm{~nm}$, and a shoulder around 800 $\mathrm{nm}$. A d-d absorption pattern displaying a low energy shoulder is characteristic for pentacoordinated copper(II) complexes possessing square pyramidal geometry or structures with a distortion towards such geometry. ${ }^{16}$ With increasing PP concentration the intensity of the low energy shoulder increases and shifts to $850 \mathrm{~nm}$, indicating a further, pronounced distortion towards sqare pyramidal geometry upon PP binding to the dinuclear complex(es).

The measured absorbances at $850 \mathrm{~nm}$ level off at $c a$. 4-fold PP excess, supporting further the strong substrate binding concluded from the substrate concentration dependent kinetic experiment.

In conclusion, the kinetic experiments support that the hydrolysis of the phosphomonoester NPP is efficiently promoted by dinuclear copper(II) complex(es) of tmci. The observed high rate enhancement for the cleavage of a phosphomonoester is surprising and rather unique among the complexes containing divalent metal ions. The efficiency is comparable or even higher than those of the active dinuclear cobalt(III) ${ }^{17}$ and lanthanide(III) ${ }^{7 \mathrm{~b}}$ complexes reported to date. Interestingly, and in contrast with the latter complexes, the present system is considerably $(\sim$ 2500-fold) less efficient for the hydrolysis of BNPP, thus highly selective for the cleavage of phosphomonoesters. The previously examined and closely related copper(II) - tdci system showed reverse selectivity, since it hydrolysed the phosphodiester BNPP 150-fold faster than NPP. ${ }^{5 b}$ Further kinetic, equilibrium and structural studies, to identify and characterize the kinetically active species and to explain the opposite selectivity of tdci and tmci complexes, are currently under way in our laboratory. 


\section{Experimental Section}

Materials. Copper(II) nitrate (Fluka) solutions were standardized complexometrically. KOH (Fluka) standard solutions were used to adjust the pH. HEPES (4-(2-Hydroxyethyl)piperazine-1ethanesulfonic acid), CHES (2-(Cyclohexylamino)ethanesulfonic acid), MES (2-(NMorpholino)ethanesulfonic acid), PP (phenyl phosphate disodium salt) (all Sigma products), NPP (4-Nitrophenyl phosphate disodium salt hexahydrate) and BNPP (Bis(4-nitrophenyl) phosphate hydrate) (Fluka) were used without further purification. The ligand tmci (tmci $3 \mathrm{HCl}$ ) was prepared $^{18}$ and purified ${ }^{13,18}$ as described earlier. The concentration of tmci stock solution was determined by potentiometry.

General procedure for kinetic measurements. The solution of the dinuclear complex(es) was prepared in situ, by mixing appropriate amounts of the stock solutions of tmci and copper(II) nitrate. The hydrolysis of NPP was followed by spectrophotometry, detecting the formation of the corresponding nitrophenolate anion at $400 \mathrm{~nm}\left(\varepsilon_{400}=18900 \mathrm{M}^{-1} \mathrm{~cm}^{-1}, \mathrm{p} K=6.98\right)^{5 \mathrm{~b}}$ in aqueous solution at $I=0.1 \mathrm{M}\left(\mathrm{KNO}_{3}\right)$ and $T=298 \mathrm{~K}$. The reported kinetic data, determined by the initial slope method ( $\leq 4 \%$ conversion) are averages of triplicate measurements (reproducibility better than 10\%). The initial concentration of the substrate varied from $0.05 \mathrm{mM}$ to $3 \mathrm{mM}$. In all cases $0.02 \mathrm{M}$ buffer (HEPES and CHES) was used. In a typical experiment, the $\mathrm{pH}$ of the solution containing $0.5 \mathrm{mM}$ tmci and $1 \mathrm{mM}$ copper(II) was adjusted to the desired value by $\mathrm{KOH}$ solution. After $5 \mathrm{~min}$ equilibration, $50 \mu \mathrm{L}$ of $0.005 \mathrm{M}$ NPP was injected into $2 \mathrm{~mL}$ solution with efficient mixing. The increase of the absorbance at $400 \mathrm{~nm}$ was then followed. Blank experiments with copper(II) free tmci solutions were also performed, but the observed rate of hydrolysis was identical with that of the NPP autohydrolysis at the given $\mathrm{pH}$.

\section{Acknowledgements}

This work was supported by the Hungarian Scientific Research Found (OTKA NI61786 and K63606). A.J. wishes to thank the Hungarian Academy of Sciences for the support of the János Bolyai Research Grant.

\section{References and Notes}

1. Williams, N. H.; Takasaki, B.; Wall, M.;Chin, J. Acc. Chem. Res. 1999, 32, 485.

2. (a) Shell, T. A.; Mohler, D. L. Curr. Org. Chem. 2007, 11, 1525. (b) Sumaoka, J.; Yamamoto, Y.; Kitamura, Y.; Komiyama, M. Curr. Org. Chem. 2007, 11, 463. (c) Morrow, J. R.; Iranzo, O.; Curr. Opin. Chem. Biol. 2004, 8, 192.

3. Verge, F.; Lebrun, C., Fontecave, M.; Ménage, S. Inorg. Chem. 2003, 42, 499. 
4. Williams, N. H.; Cheung, W.; Chin, J. J. Am. Chem. Soc. 1998, 120, 8079.

5. (a) McCue, K. P.; Morrow, J. M. Inorg. Chem. 1999, 38, 6136. (b) Gajda, T.; Düpre, Y.; Török, I.; Harmer, J.; Schweiger, A.; Sander, J.; Kuppert, D.; Hegetschweiler, K. Inorg. Chem. 2001, 40, 4918. (c) Gajda, T.; Jancso, A.; Mikkola, S.; Lönnberg, H.; Sirges, H. J. Chem. Soc., Dalton Trans. 2002, 1757. (d) Prokofieva, A.; Prikhodko, A. I.; Enyedi, É. A.; Farkas, E.; Maringgele, W.; Demeshko, S.; Dechert, S.; Meyer, F. Inorg. Chem. 2007, 46, 4298.

6. (a) Mancin, F.; Tecilla, P. New J. Chem. 2007, 31, 800. (b) Bauer-Siebenlist, B.; Meyer, F.; Farkas, E.; Vidovic, D.; Dechert, S. Chem. Eur. J. 2005, 11, 4349. (c) Iranzo, O.; Elmer, T.; Richard, J. P.; Morrow, J. R. Inorg. Chem. 2003, 42, 7737. (d) Iranzo, O, Kovalevsky, A.Y.; Morrow, J. R.; Richard, J. P. J. Am. Chem. Soc. 2003, 125, 1988. (e) Albedyhl, S.; Schnieders, D.; Jancso, A.; Gajda, T.; Krebs, B. Eur. J. Inorg. Chem. 2002, 1400. (f) Gajda, T.; Krämer, R.; Jancso, A. Eur. J. Inorg. Chem. 2000, 1635.

7. (a) Franklin, S. J. Curr. Opin. Chem. Biol. 2001, 5, 201. (b) Gomez-Tagle, P.; Yatsimirsky, A. K. Inorg. Chem. 2001, 40, 3786. (c) Komiyama, M.; Takeda, N.; Shigekawa, H. Chem. Commun. 1999, 1443.

8. Williams, N. H.; Lebuis, A.-M.; Chin, J. J. Am. Chem. Soc. 1999, 121, 3341.

9. Kövari, E.; Krämer, R. J. Am. Chem. Soc. 1996, 118, 12704.

10. Koike, T.; Inoue, M.; Kimura, E.; Shiro, M. J. Am. Chem. Soc. 1996, 118, 3091.

11. Hegetschweiler, K. Chem. Soc. Rev. 1999, 28, 239.

12. Jancsó, A.; Mikkola, S.; Lönnberg, H.; Hegetschweiler, K.; Gajda, T. Chem. Eur. J. 2003, 9, 5404.

13. Jancsó, A.; Mikkola, S.; Lönnberg, H.; Hegetschweiler, K.; Gajda, T. J. Inorg. Biochem. 2005, 99, 1283.

14. Zalatan, J. G.; Herschlag, D. J. Am. Chem. Soc. 2006, 128, 1293.

15. Kirby, A. J.; Jencks, W. P. J. Am. Chem. Soc. 1965, 87, 3209.

16. (a) Duggan M.; Ray, N.; Hathaway, B.; Tomlinson, G.; Brint, P.; Pelin, K. J. Chem. Soc., Dalton Trans. 1980, 1342. (b) Karlin, K. D.; Hayes, J. C.; Juen, S.; Hutchinson, J. P.; Zubieta, J. Inorg. Chem. 1982, 21, 4106. (c) Lee, D.-H.; Murthy, N. N.; Karlin, K. D. Inorg. Chem. 1997, 36, 5785. (d) Wei, N.; Murthy, N. N.; Karlin, K. D. Inorg. Chem. 1994, 33, 6093.

17. (a) Vance, D. H.; Czarnik, A. W. J. Am. Chem. Soc. 1993, 115, 12165. (b) Rajwi, G. H.; Yamafa, M.; Sadler, N. P.; Milburn, R. M. Inorg. Chim. Acta 2000, 303, 168.

18. Hegetschweiler, K.; Weber, M.; Huch, V.; Geue, R. J.; Rae, A. D.; Willis, A. C.; Sargeson, A. M. Inorg. Chem. 1998, 37, 6136. 